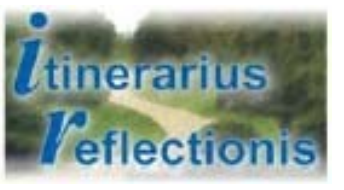

Revista de Educação do Curso de Pedagogia do Campus Avançado de Jataí da Universidade Federal de Goiás

[Vol I- n.3] [Jan/Jul] [2007]

ISSN : 1807-9342

\title{
A CULTURA E AS DIFERENTES CONCEPÇÕES APREENDIDAS NAS DETERMINAÇÕES HISTÓRICAS
}

\author{
PINTO, Suely Lima de Assis ${ }^{1}$ Docente do Curso de Pedagogia CAJ/UFG
}

\section{RESUMO}

O presente texto analisa as diferentes concepções de cultura, em seus elementos objetivos e subjetivos. Ela pode ser compreendida como objetivação das necessidades humanas externalizadas no trabalho e como subjetivação e compreensão do mundo simbólico constituído no campo ideológico. O texto ressalta ainda que a cultura se constitui não apenas enquanto trabalho ou reposição das necessidades humanas por meio dos produtos materiais gerados pelo trabalho, mas também enquanto símbolos, regras, valores, ações, modo de ser e de ver o mundo.

Palvras-Chave: cultura, educação, conhecimento.

\section{ABSTRACT}

This paper analyses the different conceptions of culture, in its subjective and objective elements. It might be understood as objetivization of human needs externalized in work, as well as subjectivation and understanding of the symbolic world set in the ideological field. The text also emphasizes that culture constitutes itself not only as work or reposition of human needs through material products generated by work, but also as symbols, rules, values, actions, and the way to be and see the world.

Key words: culture, education, knowledge.

\section{Introdução}

\begin{abstract}
A paisagem humana é necessariamente construída pelas obras culturais, pois só elas atestam ao homem a essência e o sentido da sua presença no mundo: a presença de um sujeito que compreende, transforma e significa. Elas são a objetivação da essência do homem como consciência de si.
\end{abstract}

\footnotetext{
${ }^{1}$ Mestre em Educação Brasileira - Faculdade de Educação / UFG, professora do curso de Pedagogia Campus de Jataí/UFG.
} 
Com esta afirmativa Vaz (1966, p.5) faz sua definição de cultura - a presença do homem no mundo humano. Ele nos apresenta um conceito de cultura definido em duas instâncias: cultura objetiva e cultura subjetiva. Na face objetiva da cultura, ela se apresenta nas obras culturais. Para ele, o mundo só é significativo ao homem neste movimento que opera a passagem do ser natural para o cultural. É no exercício do ato de criação cultural que o homem se realiza e emerge para o espaço humano da consciência de si mesmo. É neste espaço humano que se exprime a cultura subjetiva.

Se o mundo da cultura é o mundo no qual o homem se reconhece, diz Vaz, só a compreensão do seu sentido permite ao homem realizar-se como homem, e acrescenta, o homem é ser histórico porque transforma o mundo, cria a cultura. Este caráter social e histórico da cultura é estabelecido por meio da objetivação do sentido em obras culturais, ou seja, é a transformação do sinal subjetivo em um sentido compreendido e comunicado. Se não fosse este caráter de significações, o homem regridiria a comportamentos que o autor denomina de infra-humanos. A cultura é, então, a dimensão histórica do ser humano e, neste sentido, a definição que para Vaz melhor caracteriza essa dimensão é esta do autor Waelhens, na qual cultura é:

O processo social e histórico constituído pelas relações de conhecimento e transformação do homem como natureza e pelas relações de reconhecimento do homem com o outro homem, processo que cria um mundo humano, e através do qual o homem se realiza como homem neste mundo humano. (De Waelhens A., apud: Vaz,1966, p. 6)

É, neste sentido, que o autor concebe cultura como social e histórica, porque ela, na medida que traduz um sentido a ser compreendido, é humanizante, é o próprio sentido da presença do homem no mundo. Outros autores apontam este sentido - o momento de interação do homem com o outro - como fundamental neste processo de humanização e socialização do homem.

Segundo Vaz, a criação e a compreensão das obras culturais definem uma tarefa social e histórica, capaz de traduzir, em termos de cultura, o projeto que constitui e remete o homem à existência histórica. Isto é, em uma dimensão pessoal, a cultura passa do domínio da necessidade para o domínio da liberdade, no qual se torna possível a comunicação com o outro e o próprio projeto do existir social. É este movimento de personalização que impõe à cultura o caráter de universalidade. 
A cultura institui o reino do universal e possibilita ao homem construir um mundo histórico, ou seja, o mundo humano é construído como um mundo de significações e valores. Desta forma, afirma Vaz, as obras culturais exprimem e comprovam a consciência histórica do grupo, a forma de sua auto-realização e o índice de seu autoconhecimento.

Mesmo considerando a influência destes fatores no processo de desenvolvimento de uma determinada cultura, e embora a cultura seja apresentada por diferentes autores como o processo de humanização do homem em sua relação com o outro, percebe-se que seu caráter ideológico e alienável a desumaniza, ou seja, a cultura perde seu caráter de universalidade em função da individualização do homem, que ocorre tanto no processo de desenvolvimento do homem no trabalho, quanto nos processos de socialização do homem nesta sociedade, que é mediado pela ideologia presente na mídia e nos meios de comunicação.

Neste sentido, compreende-se que o caráter subjetivo e objetivo que apreende a definição de cultura apresentada por Vaz irá reger diferentes concepções de cultura. Se Vaz apresenta a cultura como a externalização do homem em diferentes momentos históricos, bem como a compreensão de si em si, percebe-se que esta definição de cultura assemelhase a definição de Marx (1993) e Chauí (1982), - cultura como objetivação de necessidades humanas externalizadas no trabalho, - em Geertz (1989) - cultura como subjetividade, a compreensão do mundo simbólico - e por fim a cultura compreendida no campo ideológico que é concebida tanto por Chauí quanto por Adorno (1998). Assim a presente proposta de análise do conceito de cultura pretende apresentar estes diferentes autores que a compreendem em seu caráter objetivo e subjetivo.

\section{2 - A dimensão histórica e antropológica da cultura e seu caráter ideológico.}

Uma última observação acerca do uso da expressão 'cultura do povo' concerne ao risco que poderemos correr se a encararmos romanticamente, isto é, se considerarmos que a cultura, por ser do povo, 
é imediatamente libertadora. O romantismo pode prestar serviços inestimáveis aos dominantes, seja porque atribui a este último a origem do desmantelamento da consciência de classe dos dominados, que, sem ele, teriam feito o caminho da libertação. Ora prestando serviços ao populismo, ora lastimando tê-lo deixado destroçar a autonomia da luta dos dominados, a atitude romântica é vítima de dois esquecimentos: não só esquece o problema da alienação e da reprodução da ideologia dominante pelos dominados, como também esquece de indagar se, sob o discurso 'alienado', submisso à crença nas virtudes de um poder paternalista, não se esconderia algo que ouvidos românticos não são capazes de ouvir. (Chauí, 1982, p. 46)

Iniciar uma exposição sobre o conceito de cultura tendo como enfoque a caracterização que Chaú apresenta sobre 'cultura do povo' e ouvi-la dizer que o romantismo que envolve esta concepção está a serviço dos dominantes, é o mesmo que ouvir Adorno (1998), ao falar acerca de uma visita ao museu, "só está livre do mal tão bem diagnosticado por Valéry aquele que junto com o guarda-chuva também entregou, na entrada, a sua ingenuidade" ${ }^{2}$.

Tanto Chauí quanto Adorno apontam para uma visão de cultura em que todas as determinações que envolvem uma ação cultural são impregnadas de ideologia. Neste contexto, torna-se impossível, após a influência destes autores, a permanência deste romantismo; percebe-se, também, o quanto o desvelar desta realidade assemelha-se para muitos como um desvirginar da consciência.

A proposta aqui empreendida de se compreender o conceito de cultura torna-se, neste contexto, extremamente difícil, pois, no mínimo, ela deve ser clara e concisa, sem, no entanto, deixar de ser densa, revelando, em sua essência, o poder da ideologia implícita na cultura e na indústria cultural.

$\mathrm{Na}$ ânsia de uma compreensão nesta perspectiva optou-se, inicialmente, pela exposição desse conceito com base em Chauí ${ }^{3}$. Trabalhar com a questão cultural é um grande desafio dada a multiplicidade de concepções a respeito deste termo. E, na

\footnotetext{
${ }^{2}$ No texto "Museu Valéry Proust", Adorno analisa duas concepções de museu, apresentada por dois autores, Proust e Valéry. Considera-se aqui as afirmativas que Adorno levanta no texto, de que a exposição museológica, elaborada com uma visão do dominador, é ideológica. Prost acredita na possibilidade de uma verdadeira experiência estética, Valéry a considera impossível dado seu caráter ideológico. Adorno concorda com Valéry, a não ser que a exposição seja vista com criticidade, isto é, deixando a ingenuidade na entrada do museu.

${ }^{3}$ A definição inicial aqui proposta encontra-se no livro "Convite à filosofia" de Marilena Chaú, editado pela Ática, sem data de edição.
} 
expectativa de compreender estas diferentes concepções, faz-se necessário uma reflexão sobre este conceito, inicialmente, percebida pelo senso comum.

A cultura é vista por diferentes autores como uma ação humana, um processo de humanização do homem em uma relação ao outro e consigo mesmo. É nessa relação entre os homens que surgem as diferentes concepções ressaltadas pelo senso comum. A cultura nessa perspectiva é compreendida em diferentes linhas de pensamento, podendo caracterizar-se com o conhecimento erudito; como trabalho de criação ligado às artes; e significa, também, possuir um conjunto de conhecimentos e informações compreendidas no cotidiano e nos processos de socialização.

Para Chauí, as percepções de cultura no senso comum são respaldadas em ações do cotidiano que naturalizam o comportamento humano, bem como o seu modo de viver e agir. A cultura, neste sentido, constitui uma natureza humana que definiria o homem culturalmente. Isto é, cultura é percebida como se a caracterização do gênero ou etnia fosse parte desta natureza e, portanto, definisse formas de se pensar ou agir do homem e da mulher, bem como da criança, do jovem ou do idoso, do negro ou do branco.

O conceito de cultura, para Chauí, se delineia em três campos: o primeiro, como pôde ser visto no parágrafo anterior, em uma perspectiva do senso comum, apresenta quais são os erros e ou acertos mais comumente utilizados pelas pessoas no cotidiano; o segundo, em uma perspectiva histórica, é a relação dos homens no tempo e com o tempo, podendo ser analisado em Hegel como movimento do espírito e em Marx como produção e reprodução das relações humanas no trabalho; e por último, cultura como um conceito antropológico, analisada por uma perspectiva simbólica. Aqui a natureza humana seria representada pelo homem no desenvolvimento de suas relações no seio das diferentes sociedades, principalmente, nas relações coercitivas, como normas, regras, e que formam um conjunto denominado pela antropologia como cultura.

Nesta perspectiva antropológica, Chauí define cultura em três sentidos: primeiro, a criação da ordem simbólica da lei - sistemas de interdições e obrigações estabelecidas a partir da atribuição de valores - tanto a coisas, quanto ao humano e suas relações aos acontecimentos. Em seguida, há a criação de uma ordem simbólica, na qual os símbolos surgem tanto para representar quanto para interpretar a realidade, e, como terceiro 
sentido, o conjunto de práticas, comportamentos, ações e instituições com quais os humanos se relacionam entre si e com a natureza.

A abordagem da cultura na perspectiva histórica irá refletir essa relação do homem com a natureza e com outros homens na sua produção material, momento em que seu próprio existir adquire sentido como natureza humana.

A reflexão de Chauí possibilita perceber que o desenvolvimento deste conceito se deu historicamente e que, por isso, uma mesma sociedade, sendo temporal e histórica, passa por transformações culturais amplas e, neste sentido, tanto o conceito antropológico quanto o histórico são fundamentais na construção do conceito de cultura. Considerando estes dois sentidos na análise da cultura, Chauí acrescenta um terceiro conceito, que designa a criação de obras da sensibilidade e da imaginação, as obras da inteligência e da reflexão, mas que na realidade, é este conceito que origina os preconceitos vinculados ao senso comum.

Assim, para Chauí, a cultura unida tanto nos sentidos anteriores, quanto neste último, pode ser compreendida na relação entre os homens e, desta relação, surgem diferentes caracterizações para o conceito de cultura, a saber, cultura de elite, cultura popular, cultura erudita, cultura de massa. É no escopo destes diferentes conceitos que a cultura passa a ser utilizada como instrumento de discriminação social, econômica e política.

\section{1 - As determinações que interferem no conceito de cultura}

Em uma perspectiva histórica, a cultura se apresenta nas diferentes necessidades geradas no processo de desenvolvimento do trabalho que se dá em condições determinadas e não escolhidas, nas quais os homens produzem materialmente sua cultura e dão sentidos a essa produção material.

Para Marx (1993), o homem é portador de necessidades, tem necessidades de se alimentar, vestir, e para satisfazê-las ele entra em relação com outros seres humanos, com a 
sociedade, se objetivando, desta forma, como portador de necessidades. Essas necessidades serão supridas no trabalho, no ato de vestir-se, alimentar-se, abrigar-se. Historicamente elas foram sendo atendidas, gerando, neste contexto, diferentes formas culturais de sobrevivência, ora individual, ora coletiva, mas em sua essência, produzidas historicamente.

Do ponto de vista histórico, o homem vive em uma relação de interdependência, gerado pela produção e a relação do indivíduo com o produto; essas relações são materiais e apreendidas historicamente. Segundo Marx, quanto mais se recua na História, mais dependente aparece o indivíduo, e mais amplo é o conjunto a que pertence, ou seja, o homem, para suprir suas necessidades sociais, cria a família, a tribo e as diversas formas de comunidade; o homem cria a história.

Para Marx (1993), o material do trabalho e o homem interagem por uma necessidade histórica e representam o caráter social e universal de todo o movimento de produção. Marx considera que toda atividade social do homem, comunitária ou individual, representa a expressão da sociabilidade humana. Sendo o trabalho a atividade social como fator fundante do homem como ser social, será a produção humana que Marx considerará como uma das determinações históricas fundamentais para compreensão do próprio homem na sociedade capitalista. É essa produção humana que irá gerar diferentes formas culturais de ser e viver, ocasionando transformações no campo cultural.

As transformações ocorridas no campo da cultura, na sociedade capitalista, são sempre constantes, causadas principalmente, por lutas e divisões internas. Tanto o caráter ideológico quanto a alienação são determinações que interferem no desenvolvimento dos processos culturais do indivíduo e estão presentes no contexto desta sociedade.

Por meio da ideologia, as sociedades apresentam a cultura como única e uniforme, ocultando totalmente, a divisão social interna. O poder de dominação da ideologia, para Chauí (1982), está impregnado no cotidiano social, econômico e político. Analisando historicamente o poder da classe dominante, percebe-se que a ideologia elaborava diferentes discursos que, independente das transformações históricas, era mantido por controle, por meio de um discurso competente. Em um dado momento histórico, um conhecimento era execrado, no seguinte, apropriado pelo discurso ideológico, era exaltado como o mais importante saber. 
Na concepção de Chauí, toda a vida humana se encontra mediada por diferentes discursos ideológicos. O homem relaciona-se com a vida, com seu corpo, com a natureza e demais seres humanos por meio de diferentes modelos, que em sua origem, estão mediados pela ideologia por meio de um discurso competente.

O autoritarismo e a dominação presentes na cultura de elite são outras determinações que sobrepõe a análise da cultura. Chaú, ao analisar a relação entre a cultura do povo e o autoritarismo das elites, afirma que as elites são autoritárias por natureza, principalmente quando essa mesma elite se encontra refletida na cultura do povo. Para ela as idéias dominantes de uma época são as idéias da classe dominante dessa época, que, refletidas nos padrões culturais, tornam-se mera reprodução. Ou seja, como a cultura do povo - que não é do povo - pois a cultura de elite, dominante, sobrepõe-se a do povo, é, então, sinônimo da cultura dominada. Utilizando uma frase de Walter Benjamim na qual ele afirma que todo documento de cultura é também documento de barbárie, presente, inclusive, no processo de transmissão da cultura, Chauí afirma que isso ocorre principalmente "porque a cultura dominante se realiza às expensas da violência exercida sobre aqueles que a tornam possível, seja porque a cultura dominada fica exposta a barbárie do dominante, seja, enfim, porque a cultura dos dominados exprime a barbárie a que estão submetidos". (Chauí, 1982, p. 44). É por esse motivo que ela afirma que a cultura do povo não é libertadora, pois reflete a cultura dominante.

A alienação caracteriza-se como mais uma determinação presente na análise da cultura. Ao falar de cultura popular, as pesquisas apontam para uma cultura dominada e manipulada pela classe dominante, mas, segundo Chauí, ao se acercar do conceito de alienação percebe-se que não há exemplificação suficiente capaz de desvendar uma diferenciação e identificação entre cultura popular e ideologia. Para ela, alienação, fenômeno presente na representação que os sujeitos elaboram nas relações sociais, é uma determinação objetiva da vida social no modo de produção capitalista e, por isto, ela se apodera tanto da cultura dominante quanto da dominada.

A alienação do trabalhador, na análise de Marx, se processa não apenas na relação com os produtos de seu trabalho, mas também no processo de produção. $\mathrm{O}$ trabalho é uma condição ontológica do ser, uma atividade que diferencia o homem do animal. A alienação, neste contexto, afasta o homem de sua condição genérica, sendo um dos motivos 
de sua desumanização. A interferência da alienação na esfera da cultura irá impossibilitar sua ação libertadora, podendo se estabelecer como processo de barbárie. Pode-se dizer que a cultura será o reflexo da barbárie ao qual Walter Benjamim se referiu.

A barbárie se apresenta, neste contexto, impulsionada tanto pela alienação quanto pela ideologia, que aderindo totalmente à cultura transformará a realidade em aparência do real e cultura em ideologia. É neste campo que a barbárie se instaura e o homem, por meio da cultura, se desumaniza.

\section{2 - Cultura e ideologia}

A compreensão do conceito de cultura foi enfocada em diversas áreas do conhecimento, pois a cultura se efetiva na interação do homem com o outro e nas suas relações com o trabalho. Nesta perspectiva, percebe-se a influência da sociedade, em diferentes momentos históricos, na construção deste conceito, bem como, a influência da ideologia presente nos diversos campos de atuação do homem em sociedade.

Adorno, no texto "Crítica cultural e sociedade" (1998), explora as condições ideológicas em que se encontra a cultura e como a crítica da cultura é inoperante ao lidar com seu objeto de conhecimento. Nesta lógica a crítica é apenas adesão. No escopo da expressão crítica cultural, está presente uma flagrante contradição que se apresenta, para Adorno, entre o crítico e seu objeto de análise. O crítico fala como se fosse o representante de uma natureza imaculada ou de um estágio histórico superior; no entanto, diz Adorno, ele é da mesma essência daquilo que acredita estar subjugado a seus pés.

A insuficiência do sujeito que pretende, em sua contingência e limitação julgar a violência do existente (...) torna-se insuportável quando o próprio sujeito é mediado até a sua composição mais íntima pelo conceito ao qual se contrapõe como se fosse independente e soberano. (Adorno, 1998, p. 7)

A racionalidade na qual o crítico trabalha é a mesma em que ele acredita e por isso não é possível seu distanciamento do objeto de sua crítica. Quando ele analisa um determinado produto cultural, a lógica de construção de seu pensamento opera na mesma 
lógica de construção do produto cultural analisado. Neste sentido, percebe-se o quanto a cultura que se apresenta como realidade é falsa e, ao mesmo tempo, respaldada por uma crítica velada, se configura para os indivíduos como a única realidade possível.

A liberdade de expressão que em determinados momentos históricos foi tão reprimida, em outros, onde a cultura se encontra impregnada pela ideologia do dominante, passa a ser a reprodução e a expressão do existente. Por isso não é preciso reprimir a liberdade de expressão, pois a possibilidade deste espírito de se expressar é legítima, no entanto ele vai repetir o existente. Sua liberdade de expressão não desvela a realidade impregnada de ideologia - ela não consiste na crítica do existente. A cultura se transforma em ideologia, e, como afirma Adorno,

a cultura só é verdadeira quando implicitamente crítica, e o espírito que se esquece disso vinga-se de si mesmo nos críticos que ele próprio cria. A crítica é um elemento inalienável da cultura, repleta de contradições e, apesar de toda sua inverdade, ainda é tão verdadeira quanto não-verdadeira é a cultura. A crítica não é injusta quando destrói - esta ainda seria sua melhor qualidade - mas quando, ao desobedecer, obedece. (Adorno, 1998, p. 11)

Ao obedecer, a crítica opera na mesma lógica da barbárie, a cumplicidade entre a crítica e cultura torna-se a mesma coisa, ela legitima a cultura vigente.

Para Adorno, a crítica cultural compartilha com seu objeto, o ofuscamento, e a cultura enquanto conteúdo essencial da autoconsciência não pode libertar-se dessa aparência. A idéia de consciência para ele opera na universalidade, não existe consciência singular sem a idéia de universalidade. E dentro deste contexto na qual a cultura opera, o princípio de humanidade fica suspenso nas malhas da ideologia. A noção de ideologia, diz Adorno, foi transformada de um meio de conhecimento em um meio de controle do conhecimento.

Esse controle opera em diversas esferas. A cultura, para Adorno, tornou-se ideológica também na vida privada, e se apresenta sob a aparência de importância e autonomia. É por isso que, para esse autor,

‘ideologia' significa sociedade enquanto aparência. Embora seja mediada pela totalidade, atrás da qual se esconde a dominação do parcial, a ideologia não é redutível pura e simplesmente a um interesse parcial; por isso, de certo modo, está em todas as suas partes à mesma distancia do centro.(Adorno, 1998, p. 21) 
A crítica cultural foi absolvida pela ideologia imanente à cultura. Ela é fruto da própria ideologia, daí a dificuldade de transpor a aparência do real. Adorno propõe uma crítica dialética, aquela que poderia apreender a cultura em sua totalidade, em sua essência: um método de crítica dialética, afirma Adorno, que transcenda a cultura e a rede de ofuscamento em que se encontra inserida.

Neste sentido, Adorno traça uma perspectiva pouco alentadora sobre o conceito de cultura. Totalmente aderente a lógica do mercado, a cultura se converteu em uma razão instrumental. Nesta lógica que governa a razão que se instrumentalizou, o sujeito se converte a esta racionalidade; e, mesmo tendo liberdade, escolhe a barbárie simplesmente porque não há liberdade de escolha, não há autonomia e a barbárie estará sempre travestida de liberdade, de realidade, de desejo, de sonho.

Todos estes aspectos da barbárie encontram respaldo nas promessas de satisfação da necessidade instaurada no bojo da indústria cultural. A cultura neste contexto transforma-se em pura ideologia. É a cultura dominante sobrepondo-se à cultura dominada com seus conceitos, seus valores, seu discurso, tanto nas relações sociais quanto nas relações políticas. A cultura, como aparência, torna-se, em sua essência, uma realidade velada, ideologizada.

\section{3 - A compreensão da cultura em seu caráter simbólico}

O conceito antropológico de cultura é reconhecido por diversos autores por sua dimensão simbólica, vinculada ao comportamento humano. Este processo se caracteriza nas relações entre os homens e no desenvolvimento de sua natureza humana, que se efetiva principalmente por meio da linguagem. Neste contexto, pode-se dizer que esta dimensão simbólica caracteriza-se tanto nos aspectos subjetivos da cultura quanto nos aspectos objetivos, pois a própria produção material do homem possui caráter simbólico, é cheio de significações.

Berger e Berger (1978), ao analisarem a linguagem como instituição social, demonstram como ela exerce um controle da conduta individual imposta pela sociedade. 
Neste sentido a linguagem torna-se uma instituição fundamental no desenvolvimento cultural do indivíduo principalmente porque possui um universo de significados construídos e que só existem por meio dela mesma. Desta forma, além de inserir o indivíduo nos processos culturais de sua sociedade por meio de uma socialização, a linguagem cumprirá também um papel ideológico por meio da coercitividade exercida sobre este indivíduo. A linguagem, como ação humana, será padronizada, organizada em regras distintas e principalmente carregada de significações.

Para uma melhor compreensão da cultura e sua dimensão simbólica, ressalta-se aqui o estudo elaborado por Geertz, no livro “A interpretação das culturas” (1989), no qual o autor apresenta o estudo etnográfico no âmbito da antropologia, demonstrando a importância da etnografia para o estudo das culturas. A etnografia é, dentre os ramos da antropologia, a que melhor possibilita a compreensão deste emaranhado de ações que se desenvolvem entre o indivíduo e a sociedade.

O homem é um animal amarrado a teias de significados que ele mesmo teceu, Geertz assume a cultura como sendo essas teias e sua análise, portanto, não é uma ciência experimental, mas uma ciência interpretativa, à procura de significados. Sua definição de cultura assenta-se, então, na possibilidade de interpretação desses significados.

Geertz procura refletir como os conceitos científicos importantes se desenvolvem, principalmente, no caso do conceito de cultura, em torno do qual surgiu todo o estudo da antropologia. A compreensão da ciência, para ele, está vinculada à compreensão do que fazem aqueles que a estudam, isto é, significa conhecer a etnografia, e o que define a etnografia enquanto método é uma descrição densa, termo utilizado inicialmente por Gilbert Ryle. Para este autor, segundo Geertz, uma descrição densa consiste em captar, além da imagem física, a essência do significado observado. A descrição densa do objeto da etnografia é, então, uma hierarquia estratificada de estruturas significantes onde os mínimos gestos serão interpretados.

Com base neste conceito de descrição densa, Geertz caracteriza cultura como aspectos do cotidiano de um grupo que poderão ser apreendidos por uma descrição densa. Cultura é, portanto, pública. Segundo ele, dentro da antropologia, existe um debate interminável sobre a caracterização da cultura como subjetiva ou objetiva ou se é idealista, materialista. Em sua opinião, o que se deve perguntar sobre cultura não é se as ações 
humanas observadas têm um status ontológico e sim qual é a sua importância, ou seja, o que se pretende transmitir com sua ocorrência, e por meio do sentido simbólico ${ }^{4}$, o que está sendo transmitido. Mesmo considerando esta questão como óbvia, Geertz afirma que ela pode ser obscurecida em duas formas:

uma delas é imaginar que a cultura é uma realidade "superorgânica" outocontida, com forças e propósitos em si mesma, isto é, reificá-la. Outra é alegar que ela consiste no padrão bruto de acontecimentos comportamentais que de fato observamos ocorrer em uma ou outra comunidade identificável - isso significa reduzi-la. (...) a cultura é composta de estruturas psicológicas por meio das quais os indivíduos ou grupos de indivíduos guiam seu comportamento. (Geertz, 1989, p. 21)

Por isto, para ele, descrever uma cultura é elaborar regras sistemáticas, que possibilitaria ao indivíduo passar como membro de outra cultura. Como resultado desta análise, seria refletido o que realmente pensam os membros do grupo analisado, ou se seria apenas simulações inteligentes, porém diferentes do que eles pensam. Ao se chegar a um determinado grupo, deve-se compreender o sentido simbólico do gesto, para não agir de forma que em outra cultura possa ser interpretado diferentemente.

Geertz evidencia que na análise de significados existem diferentes teorias, mas deve-se considerar que a falta de familiaridade com o universo imaginativo de determinado grupo, cujos atos são marcos determinados, demonstra que o ser humano pode ser um enigma. Por mais que se conheça determinado grupo, não é possível situar-se entre seus membros. Situar-se dentro de um grupo é uma ação enervante que só pode ser bem sucedida parcialmente - nisto consiste a pesquisa etnográfica.

Uma das ações mais difíceis da pesquisa etnográfica, segundo Geertz, é conversar com membros do grupo analisado, e por isso, um dos objetivos da antropologia passa a ser o alargamento do universo do discurso humano. Neste sentido, percebe-se que

como sistemas entrelaçados de signos interpretáveis (o que eu chamaria símbolos, ignorando as utilizações provinciais), a cultura não é um poder, algo ao qual podem ser atribuídos casualmente os acontecimentos sociais, os comportamentos, as instituições ou os processos; ela é o contexto, algo dentro do qual eles podem ser descritos de forma inteligível - isto é, descritos com densidade”. (Geertz, 1989, p. 24)

\footnotetext{
${ }^{4}$ Quando Geertz menciona o sentido simbólico, ele exemplifica com a ação humana de piscar. Este piscar pode ser um tique nervoso ou um sinal para um amigo. Em uma descrição densa o pesquisador deverá apreender o sentido do gesto observado.
} 
Compreender a cultura de um povo, diz Geertz, expõe a sua normalidade sem reduzir sua particularidade, e, compreender o que é interpretação antropológica e em que grau ela é interpretação - com base no que ela se propõe ou não a dizer - consiste nas formulações ou interpretações dos sistemas simbólicos de outros povos, que, para Geertz, devem ser orientados pelos atos, isto é, 'ver as coisas do ponto de vista do ator'.

As análises aqui levantadas por Geertz levam a uma compreensão substancial, de que os textos antropológicos são na verdade interpretações de segunda e terceira mão. Para ele, somente o informante faz a primeira interpretação - é a sua cultura. A análise do antropólogo interpretará a essência da cultura analisada. Geertz vai denominá-la como uma interpretação fictícia. Fictícia no sentido de algo construído, algo modelado, e que às vezes é difícil convencer o antropólogo deste fato. Eles devem saber interpretar, principalmente, a simbologia dos gestos observados.

A cultura é, então, uma noção de comportamento apreendido. É através do fluxo do comportamento que as formas culturais encontram articulação, mas também em várias espécies de artefatos e vários estados de consciência. A interpretação antropológica, neste contexto, irá construir a leitura do que acontece - é a descrição densa, elaborada pelo antropólogo, que levará a essência da cultura analisada.

O autor ressalta que a ênfase na descrição densa e na compreensão dos símbolos é um argumento no sentido de que remodelar o padrão das relações sociais é reordenar as coordenadas do mundo experimentado. Para ele, fugir destas análises teóricas é transformar a cultura em folclore, em instituições, em estruturas, e isto seria fazer da cultura objeto de coleção, classificação e brincadeira, o que ele considera apenas como fugas.

Nesta análise da cultura, a posição de Geertz é manter a análise das formas simbólicas o mais estreito possível com os acontecimentos sociais e ocasionais concretos, organizando as formulações teóricas com as interpretações descritivas. Para Geertz, é fundamental olhar as dimensões simbólicas da ação social - arte, religião, ideologia, ciência, lei, moralidade, senso comum e não se afastar dos dilemas existenciais da vida e sim mergulhar no meio delas.

Assim, percebe-se que ele enfatiza a etnografia e a necessidade de se compreender a importância da dimensão simbólica na compreensão do conceito de cultura, enfocando, na dimensão deste olhar, todas as possibilidades de interpretações simbólicas 
contidas nas diferentes determinações que envolvem a construção deste conceito. É uma tarefa árdua para quem vislumbra a cultura como objeto de pesquisa, dado seu caráter ideológico, mas é justamente a possibilidade deste desvelar da ciência que incita o pesquisador à efetivação desta tarefa.

\section{3 - À guisa de conclusão}

Considerando os aspectos aqui expostos sobre o conceito de cultura, compreende-se que ela estará sempre sendo reinterpretada por diferentes autores em diferentes épocas históricas. Isso demonstra uma dimensão de movimento no curso da história. A cultura se constitui não só enquanto trabalho, ou reposição das necessidades humanas por meio dos produtos materiais gerados pelo trabalho, mas se constitui também enquanto símbolos, regras, valores, ações, modo de ser e de ver o mundo. Neste sentido ela se cria, se recria, se forma, se transforma, se externaliza, se objetiva e principalmente, se universaliza.

O caráter universal da cultura, que possibilita ao homem "ser humano", é que gera a possibilidade de uma formação humana não calcada na barbárie, tão empreendida por Adorno (1991) e outros autores. No entanto, a análise aqui apresentada demonstra que a cultura não pode ser pensada por meio de um romantismo, é fundamental a criticidade do pesquisador para a compreensão da ideologia que impregna as entranhas da sociedade.

Assim compreende-se que, de acordo com os autores aqui apresentados (Chauí, Marx, Adorno, Berger e Berger, Geertz), não se deve estudar uma cultura sem analisar as determinações que a compõem e as ideologias às quais está sujeita, bem como considerar a influência da sociedade no desenvolvimento da cultura, implícito na sua simbologia.

É neste sentido que a universalidade da cultura se quebra para se constituir em objeto de dominação e discriminação social e política. $\mathrm{O}$ caráter libertador da cultura neste contexto se torna utópico, mas, como utopia, pode vir a se efetivar em um novo momento

histórico. É por isto que o conceito de cultura, neste trabalho, não se conclui, pois, no curso 
do movimento histórico, pode se deparar com uma realidade cultural - utopicamente desvelada. 


\section{4 - Bibliografia}

ADORNO, T. W. e HORKHEIMER, M. Temas básicos da sociologia. Trad. de Álvaro Cabral. São Paulo: Cultrix e Editora da USP, 1973.

. Crítica cultural e sociedade. In: Prismas. São Paulo: Ática, 1998. p. 7-26. e Horkheimer, Max. Dialética do esclarecimento. Rio de Janeiro: Zahar, 1991.

BERGER, Peter L. e BERGER, Bigitte. O que é uma instituição social? In: FORACCHI, Marialice Mencarini e MARTINS, José de Souza. Sociologia e sociedade: leituras de introdução à sociologia. Rio de Janeiro: Livros Técnicos e Científicos, 1978.

CHAUÍ, Marilena. Cultura e democracia: o discurso competente e outras falas. 3 ed. São Paulo: Moderna, 1982.

. Convite à filosofia. São Paulo: Ática. S/d.

IANNI, Otávio. Dialética e capitalismo: ensaio sobre o pensamento de Marx. Petrópolis, RJ: Vozes, 1988.

GEERTZ, Clifford. A interpretação das culturas. Rio de Janeiro: Livros Técnicos e Científicos, 1989.

LARAIA, Roque. Cultura: um conceito antropológico. Rio de Janeiro: Zahar, 1988. 116 p. $90 \mathrm{p}$.

MARX, Karl. Introdução à crítica da economia política. In: $O$ capital. Trad. de Régis Barbosa e Flávio R. Kothe. 2ed. São Paulo: Nova Cultural, 1985.

1993.

. Manuscritos econômicos e filosóficos. Textos escolhidos. Lisboa: Edições 70,

VAZ S. J., Henrique de Lima. Cultura e universidade. Petrópolis, RJ: Vozes, 1966. (Coleção educar para a vida. V. 10). 